Phosphorus Research.Bulletin Vol. 16 (2003), 65-74

\title{
ADSORPTION OF HUMIC ACID ON HYDROXYAPATITES
}

\author{
TAKESHI MORIGUCHI and KAZUYUKI YANO \\ Department of Chemistry, Saitama Medical School, 981 Kawakado, Moroyama- \\ machi, Iruma-gun, Saitama 350-0496, Japan \\ SOUHEI NAKAGAWA and FUMIHIRO KAJI \\ Department of Research and Development, Taihei Chemical Industrial Co., LTD., \\ 1-1 Takayasu, Ikaruga-cho, Ikoma-gun, Nara 636-0104, Japan
}

\begin{abstract}
Adsorption of humic acid (commercially available) on hydroxyapatites (HAP-100, HAP-200, HAP-300, HAP-400) was investigated in water at $25^{\circ} \mathrm{C}$ for 6h. Among the apatites, HAP-300, which has the largest specific surface area, indicated the highest adsorbability. Adsorption with HAP-300 within 15 min indicated higher adsorbability than that with charcoal. The isothermic curves according to Langmuir and Freundlich equations revealed that adsorbability of HAP-300 was higher than that of charcoal in the case of low concentration of humic acid (less than $6.56 \mathrm{mg} / \mathrm{L}$ ). Since the adsorption was improved in $\mathrm{NaOH}$ solution than in water, we consider that humic acid is electrostatically adsorbed on Ca sites of hydroxapatite surface unlike charcoal, which shows physical adsorption into its micro pores. The hydroxyapatite may be applied to an adsorbent alternative for charcoal in water purification plants.
\end{abstract}

\section{INTRODUCTION}

We have studied adsorption of alizarin red $S$ on hydroxyapatite HAP-300, and elucidated its mechanism by FT-IR microspectroscopy: The adsorption takes place by electrostatic and chelating interactions between the apatic $\mathrm{Ca}$ sites and phenolate ions of alizarin red S. ${ }^{1} \quad$ As a further possible application, we had an interest to investigate adsorption of humic acid (HA) on HAP-300 in aqueous media.

$\mathrm{HA}$ is a heterogeneous mixture of naturally occurring organic materials, which arise from the decay of plant and animal residues in the environment. ${ }^{2}$ HA features the following properties: it has a high molecular weight, approximately $M_{n}=1.7 \mathrm{kD}, \mathrm{M}_{\mathrm{w}}=$ $3.3 \mathrm{kD} ;{ }^{3}$ it has functional groups such as phenolic $\mathrm{OH}$, carboxyl, and aryl groups identified by IR and $\mathrm{NMR}^{4}$ it exists as an anionic macromolecular electrolyte to

Received August 28, 2003; Accepted December 10, 2003 
effectively bind with many metal cations in aqueous media. ${ }^{5}$ In rivers and lakes, HA causes one of brown colored materials. For the purpose of decolorization, aluminum aggregation and charcoal adsorption were used in water purification plants. ${ }^{6}$ However, a slight amount of remaining HA becomes a source of mutagenic organic chlorides ${ }^{7}$ by chlorine treatment for sterilization.

From viewpoint of developing more efficient way of removing HA, hydroxyapatite is possibly proper as an adsorbent for the reason that cationic polar $\mathrm{Ca}$ exposed on apatic surface is expected to bind with anionic humic acid molecules in water. Therefore, we investigated adsorption of humic acid on hydroxyapatites in water, and discussed adsorption mechanism of hydroxyapatite, in comparison with charcoal adsorption.

\section{EXPERIMENTAL SECTION}

\section{Materials}

Hydroxyapatites HAP-100, HAP-200, HAP-300, and HAP-400 were prepared according to the previous method. ${ }^{8,9}$ Namely, HAP-100 was prepared by dropping phosphoric acid into calcium hydroxide slurry, HAP-200 by mixing slurries of calcium hydrogen phosphate anhydride and calcium carbonate, HAP-300 by mixing slurries of calcium hydrogen phosphate dihydrate and calcium carbonate, and HAP-400 by mixing slurries of calcium hydrogen phosphate dihydrate and sodium hydroxide. Charcoal (activated carbon powder) was purchased (Wako Pure Chemical Industry, Osaka, Japan) and used without further purification. Specific surface areas of hydroxyapatites and charcoal were measured by BET method with a high speed gas sorption analyzer, NOVA 1000 N10-12 (Yuasa Ionics Co., Ltd., Tokyo, Japan). HA (purchased from Wako) was dissolved with $0.1 \mathrm{M}$ aqueous $\mathrm{NaOH}$ and purified $^{10}$ by filtration of the $\mathrm{NaOH}$ solution through $5 \mathrm{C}$ filter paper and reprecipitation from the filtrate with conc. $\mathrm{HCl}$. After recovering the precipitate by centrifuging, the purified HA was obtained by freezedrying.

\section{Preparation of HA solutions}

The purified HA was solubilized in distilled water by using an ultrasonicator US-3 (Iuchi Co., Ltd., Tokyo, Japan). After filtration of the solution via a $0.45 \mu \mathrm{m}$ Millipore filter DISMIC-13HP (ADVANTEC Toyo Roshi Kaisha Co., Ltd., Tokyo, Japan), the 
filtrate was measured by a UV-VIS spectrometer U-2000 (Hitachi Co., Ltd., Tokyo, Japan). The accurate concentration was evaluated from the mean of absorbances at 250 , 350 , and $450 \mathrm{~nm}$, since the spectra show monotonic featureless decrease in absorbance with increasing wavelength. ${ }^{4}$ One of the spectra in the present study is indicated in FIGURE 1. The obtained solution was used for an adsorption test. In addition, HA solution in aqueous $\mathrm{NaOH}$ was prepared by solubilizing the purified HA with $0.1 \mathrm{M}$ aqueous $\mathrm{NaOH}$, and the solubilized $\mathrm{HA}$ solution was directly used for the adsorption test without filtration. Both types of HA solutions were analyzed with a $\mathrm{pH}$ meter PL-5D (Fuji Kagaku Co., Ltd., Tokyo, Japan).

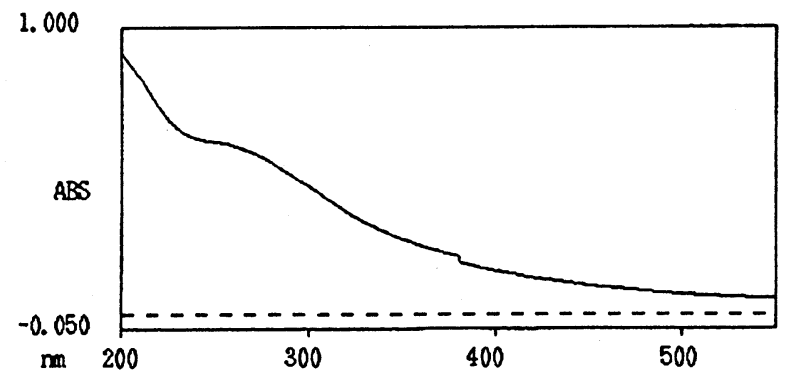

FIGURE 1 A UV-VIS spectrum of $\mathrm{HA}$ solution in water $(7.6 \mathrm{mg} / \mathrm{L})$.

\section{Adsorption test}

The solution of $\mathrm{HA}$ in water or aqueous $\mathrm{NaOH}(7.6 \mathrm{mg} / \mathrm{L}, 10 \mathrm{~mL})$ was added to adsorbent $(20 \mathrm{mg})$ in a $30 \mathrm{~mL}$ brownish bottle with a screw cap. The mixture was vigorously shaken at $25^{\circ} \mathrm{C}$ for $15 \mathrm{~min}$ to $10 \mathrm{~h}$ with a water incubator $\mathrm{M}-100^{\mathrm{N}}$ (TAITEC Co., Ltd., Saitama, Japan). The mixture was filtered via a $0.45 \mu \mathrm{m}$ Millipore filter, and the filtrate was analyzed by UV-VIS spectrometry to evaluate adsorption quantity from the mean of absorbances at 250,350 , and $450 \mathrm{~nm}$. In making isothermic curves (Langmuir and Freundlich), a mixture of $20 \mathrm{~mL}$ of HA solutions (4.0-16 mg/L) and 10 $\mathrm{mg}$ of adsorbent (HAP-300 or charcoal) was shaken at $25^{\circ} \mathrm{C}$ for $6 \mathrm{~h}$.

\section{RESULTS AND DISCUSSION}

To search equilibrium time for HA adsorption on hydroxyapatite, an adsorption test was carried out with HAP-300 for 15 min to $10 \mathrm{~h}$. As shown in FIGURE 2, the adsorption was almost equilibrated in $15 \mathrm{~min}$. However, we confirmed that the 
complete equilibrium was accomplished for 6 h. The adsorption quantity was $3.56 \mathrm{mg} / \mathrm{g}$ (TABLE 1).

As a comparison, adsorptions of $\mathrm{HA}$ with the other hydroxyapatites HAP-100, HAP-200, and HAP-400 were also investigated under the same equilibrated condition $\left(25^{\circ} \mathrm{C}, 6 \mathrm{~h}\right)$. As shown in TABLE 1 , an order of adsorption quantities is HAP-300 > HAP-100 > HAP-200, and seemingly related with that of the specific surface areas. Although HAP-400 has larger specific surface area than HAP-200, HAP-400 indicated the

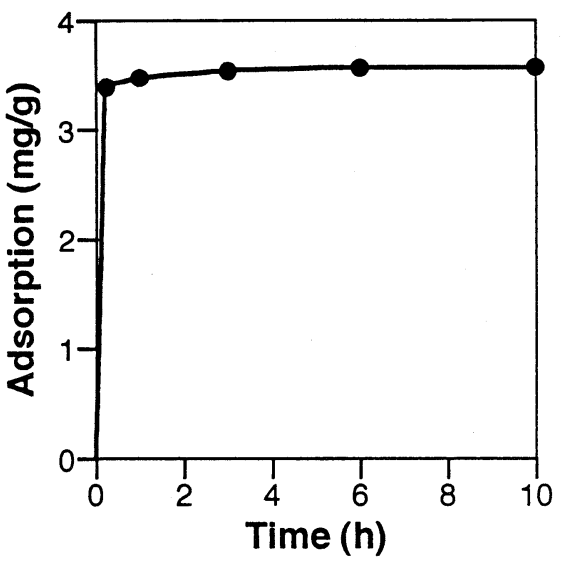

FIGURE 2 Time-adsorption curve in adsorption of HA on $\mathrm{HAP}-300$ at $25^{\circ} \mathrm{C}$ for $10 \mathrm{~h}$. fewest adsorption quantity. The ratios $\mathrm{Ca} / \mathrm{P}$ in HAP-100, HAP-200, and HAP-300 indicate stoichiometric values, while the case in HAP-400 indicates non-stoichiometric or Ca-less value. Therefore, the Ca sites on the apatic surfaces are essential and regarded as a binding site of negative-charged HA.

TABLE 1 Adsorption of HA on hydroxyapatites and charcoal in water at $25^{\circ} \mathrm{C}$.

\begin{tabular}{|c|c|c|c|c|}
\hline Adsorbent $^{a)}$ & $\begin{array}{l}\text { Specific Surface } \\
\text { Area }\left(\mathrm{m}^{2} / \mathrm{g}\right)^{b)}\end{array}$ & $\mathrm{Ca} / \mathrm{P}^{()}$ & $\begin{array}{l}\text { Adsorption } \\
\text { Time }\end{array}$ & $\begin{array}{c}\text { Adsorption } \\
\text { Quantity (mg/g) }\end{array}$ \\
\hline HAP-100 & 59.6 & 1.67 & $6 \mathrm{~h}$ & 3.37 \\
\hline HAP-200 & 8.5 & 1.69 & $6 \mathrm{~h}$ & 2.47 \\
\hline \multirow[t]{2}{*}{ HAP-300 } & 80.7 & 1.68 & $15 \mathrm{~min}$ & 3.39 \\
\hline & & & $6 \mathrm{~h}$ & 3.56 \\
\hline HAP-400 & 40.8 & 1.41 & $6 \mathrm{~h}$ & 2.42 \\
\hline \multirow[t]{2}{*}{ Charcoal } & 1430 & - & $15 \mathrm{~min}$ & 3.26 \\
\hline & & & $6 \mathrm{~h}$ & 3.66 \\
\hline
\end{tabular}

a) $20 \mathrm{mg}$, b) BET method, c) calculated from elemental analysis (references 8,9 )

Further, adsorption of HA on charcoal was carried out. Charcoal adsorbed more quantity of HA for $6 \mathrm{~h}$ than HAP-300, but less quantity for 15 min. Namely, HAP-300 
adsorbed HA faster than charcoal at early stage before adsorption equilibrium is accomplished. This phenomenon is possibly derived from the following different interactions with HA molecules having large hydrodynamic sizes ${ }^{2}(2.6-3.6 \mathrm{~nm})$ and negative-charges: HAP-300 makes an efficient electrostatic bind with HA molecules via the $\mathrm{Ca}$ sites on its surface, whereas charcoal is a little difficult to incorporate HA molecules into its fine pores ( $3.2 \mathrm{~nm}$, BET method).

In order to elucidate adsorption mechanism, adsorption of HA on HAP-300 and charcoal were carried out in water and $0.1 \mathrm{M} \mathrm{NaOH}$ at $25^{\circ} \mathrm{C}$ for $6 \mathrm{~h}$, and the data were used for plotting with both equations of Langmuir ${ }^{11}$ (EQUATION 1) and Freundlich ${ }^{12}$ (EQUATION 2).

$\mathrm{Q} / \mathrm{C}=1 / \mathrm{AQ}_{\mathrm{S}}+\mathrm{C} / \mathrm{Q}_{\mathrm{S}}$

$\mathrm{C}$ : equilibrium concentration (mg/L), Q: adsorption quantity $(\mathrm{mg} / \mathrm{g}), \mathrm{A}$ : equilibrium constant $(\mathrm{L} / \mathrm{mg}), \mathrm{Q}_{\mathrm{s}}$ : saturated adsorption $(\mathrm{mg} / \mathrm{g})$.

$\log Q=\log K_{F}+(1 / n) \log C$

C: equilibrium concentration $(\mathrm{mg} / \mathrm{L}), \mathrm{Q}$ : adsorption quantity $(\mathrm{mg} / \mathrm{g}), \mathrm{K}_{\mathrm{F}}$ $(\mathrm{mg} / \mathrm{g})(\mathrm{L} / \mathrm{mg})^{1 / \mathrm{n}}$ and $1 / \mathrm{n}:$ adsorption constants meaning affinity
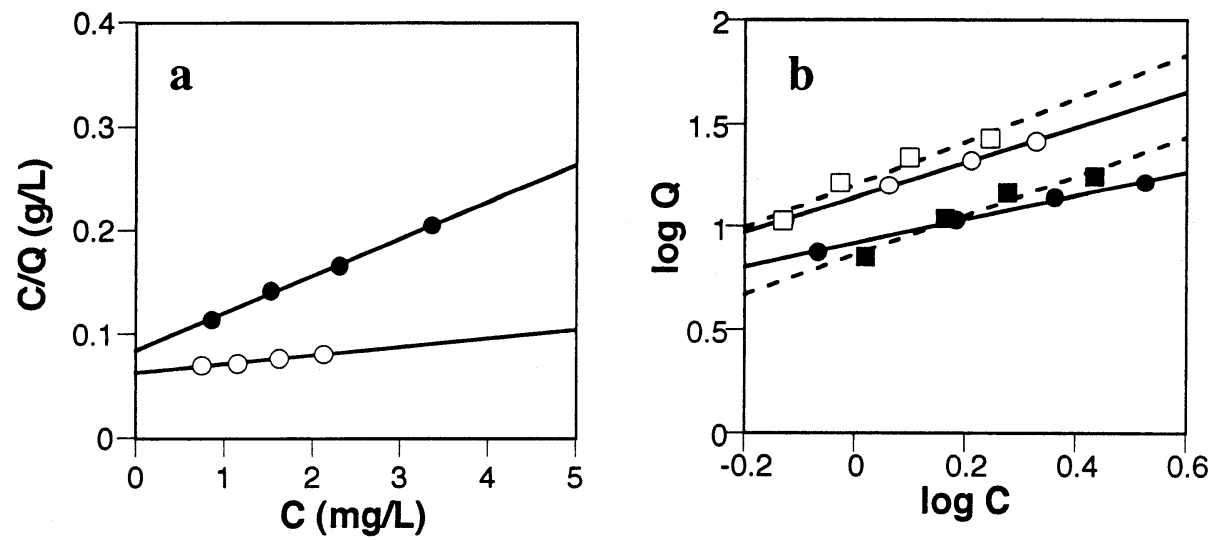

FIGURE 2 Langmuir (a) and Freundlich (b) plottings in adsorption of HA on HAP300 and charcoal in water and $0.1 \mathrm{M} \mathrm{NaOH}$ at $25^{\circ} \mathrm{C}$ for $6 \mathrm{~h}$.

-, HAP-300 in water; O, HAP-300 in $0.1 \mathrm{M} \mathrm{NaOH}$;

$\square$, charcoal in water; $\square$, charcoal in $0.1 \mathrm{M} \mathrm{NaOH}$. 
TABLE 2 Langmuir and Freundlich constants in adsorption of HA on HAP-300 and charcoal in water and $0.1 \mathrm{M} \mathrm{NaOH}$ at $25^{\circ} \mathrm{C}$ for $6 \mathrm{~h}$

\begin{tabular}{|c|c|c|c|c|c|}
\hline \multirow[b]{2}{*}{ Adsorbent } & \multirow[b]{2}{*}{ Solvent } & \multicolumn{2}{|c|}{ Langmuir } & \multicolumn{2}{|l|}{ Freundlich } \\
\hline & & $\begin{array}{c}\mathrm{Q}_{\mathrm{s}} \\
(\mathrm{mg} / \mathrm{g})\end{array}$ & $\frac{\mathrm{A}}{(\mathrm{L} / \mathrm{mg})}$ & $\underset{(\mathrm{mg} / \mathrm{g})(\mathrm{L} / \mathrm{mg})^{1 / \mathrm{n}}}{\mathrm{K}_{\mathrm{F}}}$ & $1 / \mathrm{n}$ \\
\hline \multirow[t]{2}{*}{ HAP-300 } & water & 28 & 0.42 & 8.3 & 0.58 \\
\hline & $0.1 \mathrm{M} \mathrm{NaOH}$ & 121 & 0.13 & 13.9 & 0.85 \\
\hline \multirow[t]{2}{*}{ Charcoal } & water & ND & ND & 7.3 & 0.96 \\
\hline & $0.1 \mathrm{M} \mathrm{NaOH}$ & ND & ND & 16.0 & 1.04 \\
\hline
\end{tabular}

ND: not determined.

All plottings obtained were estimated to be whether they have linear relationships or not. In Langmuir plotting (FIGURE 3a), adsorptions with HAP-300 in both water and aqueous $\mathrm{NaOH}$ resulted in linear relationships (both correlation coefficients $\mathrm{R}=$ 0.99), but adsorptions with charcoal gave no linear relationships $(R<0.4)$ to omit the plotting from FIGURE 2a. In Freundlich plotting (FIGURE 3b), all adsorptions resulted in linear relationships $(R=0.97 \sim 0.99)$. From these graphs, the constants, $Q_{s}, A$, $\mathrm{K}_{\mathrm{F}}$, and $1 / \mathrm{n}$, in EQUATION 1 and 2 were evaluated and summarized in TABLE 2. Apparently judging from the constants except for the constant A in TABLE 2, aqueous $\mathrm{NaOH}$ causes improving adsorbability of the hydroxyapatite. HA water solution (7.6 $\mathrm{mg} / \mathrm{L}$ ) was weakly acidic in $\mathrm{pH} 5.77$, while the $\mathrm{NaOH}$ solution (the same concentration) was strongly basic in $\mathrm{pH} 12.74$. The phenolic $\mathrm{OH}$ and $\mathrm{COOH}$ groups of $\mathrm{HA}$ should be more equilibrated toward dissociation $\left(\mathrm{O}^{-}, \mathrm{COO}^{-}\right)$in the basic solution to give more negative-charged HA. The higher adsorbability in aqueous $\mathrm{NaOH}$ is undoubtedly due to improving dissociation of phenolic $\mathrm{OH}$ and $\mathrm{COOH}$ in HA. Thereby HA molecules are strongly interacted with $\mathrm{Ca}$ sites on hydroxyapatite surface. Charcoal simultaneously improved its adsorbability in aqueous $\mathrm{NaOH}$. The adsorbability is dependent on aggregation property of HA molecules: the molecules are hardly aggregated in basic solution to exist as small independent molecules rather than large colloids unlike the case of water. ${ }^{13}$ Consequently, charcoal is facile to incorporate the HA molecules into its micro pores.

With a particular attention in the case of water, the $\mathrm{K}_{\mathrm{F}}$ value for HAP-300 is higher than that for charcoal in TABLE 2. The two plottings $(\boldsymbol{\square}, \mathbf{a})$ for water in FIGURE $2 b$ 
also indicate higher adsorbability of HAP-300 than that of charcoal under HA concentration lower than the cross point $X$ in FIGURE $2 b$. The equilibrium concentration $\mathrm{C}$ and adsorption quantity $\mathrm{Q}$ on this point can be calculated: $\mathrm{C}$ is 1.42 $\mathrm{mg} / \mathrm{L}$ and $\mathrm{Q}$ is $10.26 \mathrm{mg} / \mathrm{g}$. Further, adopting the present investigation condition (adsorbent weight $10 \mathrm{mg}$, solution volume $20 \mathrm{~mL}$ ), the initial concentration of $\mathrm{HA}, \mathrm{C}_{0}$ becomes $6.56 \mathrm{mg} / \mathrm{L}$ by using the equation for adsorption quantity $\mathrm{Q}=\mathrm{V}\left(\mathrm{C}_{0}-\mathrm{C}\right) / \mathrm{M}$, where $\mathrm{V}$ is solution volume $(\mathrm{L})$ and $\mathrm{M}$ is adsorbent weight $(\mathrm{g})$. Therefore, in the case that $\mathrm{C}_{0}$ is less than $6.56 \mathrm{mg} / \mathrm{L}$ under the present condition, the hydroxyapatite reveals higher adsorbability than charcoal. Similarly in the larger scale, its adsorbability will probably remain higher than that of charcoal unless the combination ratio of initial concentration, solution volume, and adsorbent weight is changed.
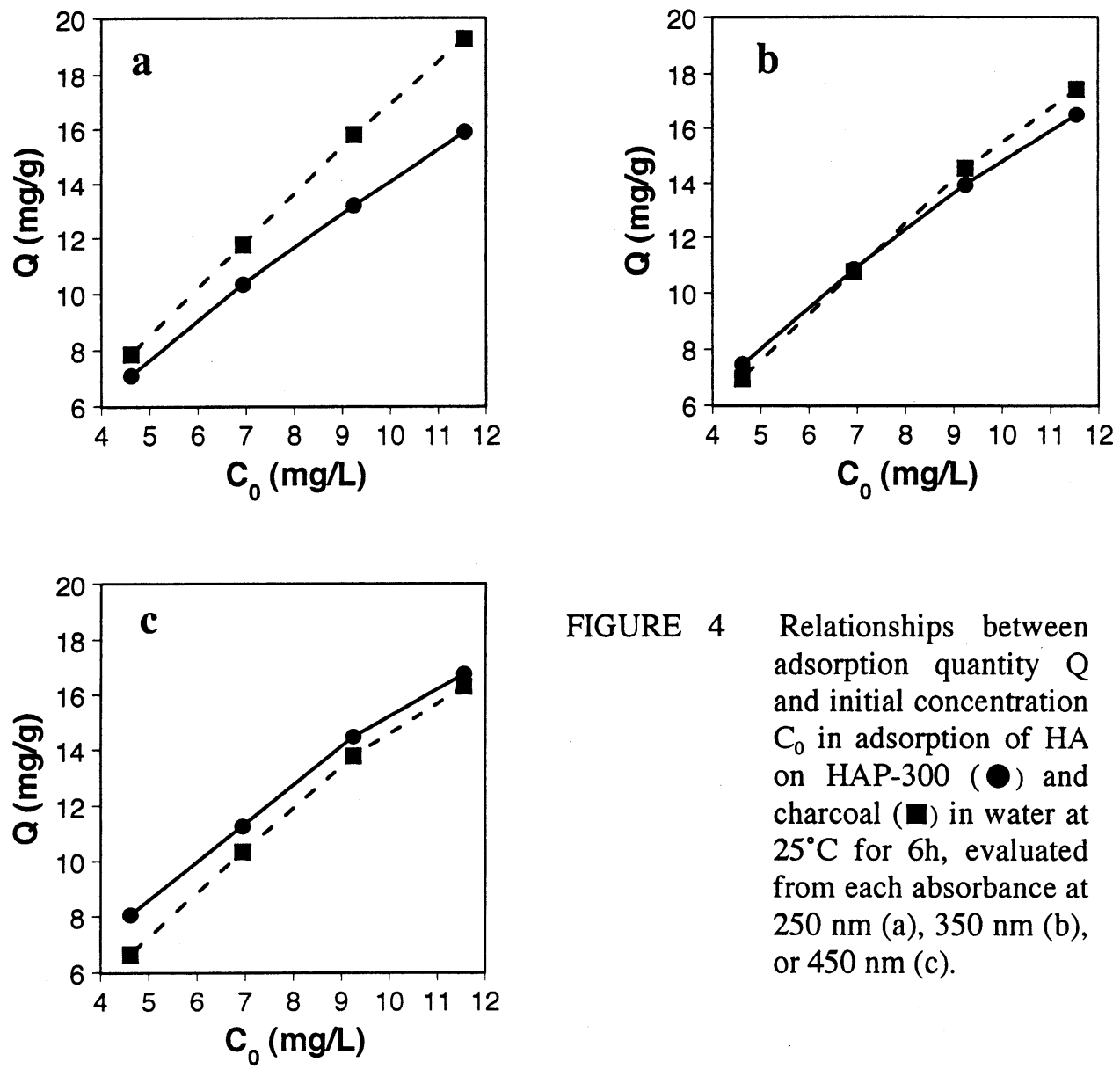

FIGURE 4 Relationships between adsorption quantity $Q$ and initial concentration $\mathrm{C}_{0}$ in adsorption of $\mathrm{HA}$ on HAP-300 (O) and charcoal (耳) in water at $25^{\circ} \mathrm{C}$ for $6 \mathrm{~h}$, evaluated from each absorbance at $250 \mathrm{~nm}$ (a), $350 \mathrm{~nm}$ (b), or $450 \mathrm{~nm}$ (c). 
To further elucidate the higher adsorbability of HAP-300 in water, three graphs are shown in FIGURE 4, plotted with adsorption quantity Q, which is evaluated from each UV-VIS absorbance at 250,350 , or $450 \mathrm{~nm}$, versus initial HA concentration $\mathrm{C}_{0}$. The graph for $250 \mathrm{~nm}$ (FIGURE 4a) reveals that adsorbability of charcoal is higher than that of HAP-300 in all $\mathrm{C}_{0}$. In the graph for $350 \mathrm{~nm}$ (FIGURE 4b), adsorbability of HAP-300 shows higher only under $\mathrm{C}_{0}$ lower than about $7 \mathrm{mg} / \mathrm{L}$. The graph for $450 \mathrm{~nm}$ (FIGURE $4 \mathrm{c}$ ) indicates the opposite case of $250 \mathrm{~nm}$ : HAP-300 adsorbed more HA molecules than charcoal in all $\mathrm{C}_{0}$. In general, molecules absorbed at longer wavelength in UV-VIS spectroscopy have large conjugated forms and/or functional groups $(\mathrm{OH}, \mathrm{COOH}$, etc.) on benzene rings. ${ }^{14,15}$ Thereby, the molecules absorbed at $450 \mathrm{~nm}$ are possibly composed of considerably large molecules and/or many functional groups such as phenolic $\mathrm{OH}$ and $\mathrm{COOH}$, whereas those absorbed at $250 \mathrm{~nm}$ are possibly composed of small molecules and/or a few functional groups. The former molecules should be hydrophilic but the latter ones hydrophobic. The molecules absorbed at $350 \mathrm{~nm}$ possibly indicate a medium character between the case of 250 and $450 \mathrm{~nm}$. Therefore, HAP-300 well adsorbs large-sized, highly negative-charged, and hydrophilic HA (electrostatic adsorption), while charcoal predominantly adsorbs small-sized, lower negative-charged, and hydrophobic HA (physical adsorption), as shown in SCHEME 1. The higher adsorbability of HAP-300 than that of charcoal in water under low HA concentration $\left(\mathrm{C}_{0}\right.$ $<5.65 \mathrm{mg} / \mathrm{L}$ ) is ascribed to considerably strong interaction with the HA molecules, which is particularly absorbed at wavelength values more than $350 \mathrm{~nm}$.

\section{CONCLUSIONS}

We have found that HAP-300 shows higher adsorbability to HA in water than charcoal in the case of short adsorption time ( $<15 \mathrm{~min})$ and of low concentration of HA $\left(\mathrm{C}_{0}<6.56 \mathrm{mg} / \mathrm{L}\right)$. Since statistics ${ }^{16}$ shows that the mean concentration of $\mathrm{HA}$ substances in rivers and lakes is included in $0.5-4.0 \mathrm{mgC} / \mathrm{L}$ (based on carbon quantity in $\mathrm{HA}$ ), or approximately in $1.0-8.0 \mathrm{mg} / \mathrm{L}$ (based on HA itself), the hydroxyapatite may be possibly applied to an adsorbent as an alternative to charcoal, filled in a short column equipped in water purification plants. Now, the further study is in progress by using aquatic humic substances. 


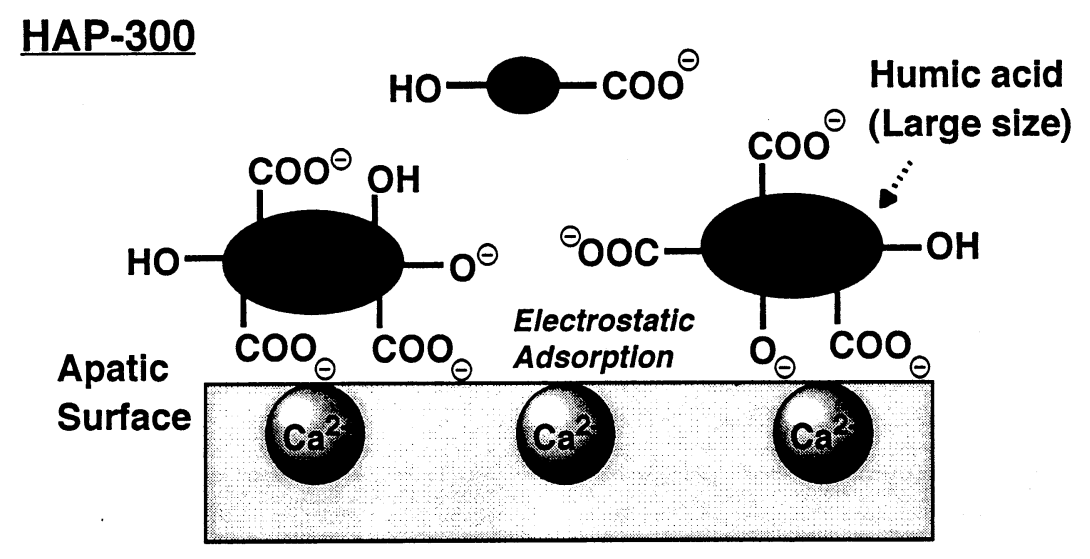

\section{Charcoal}

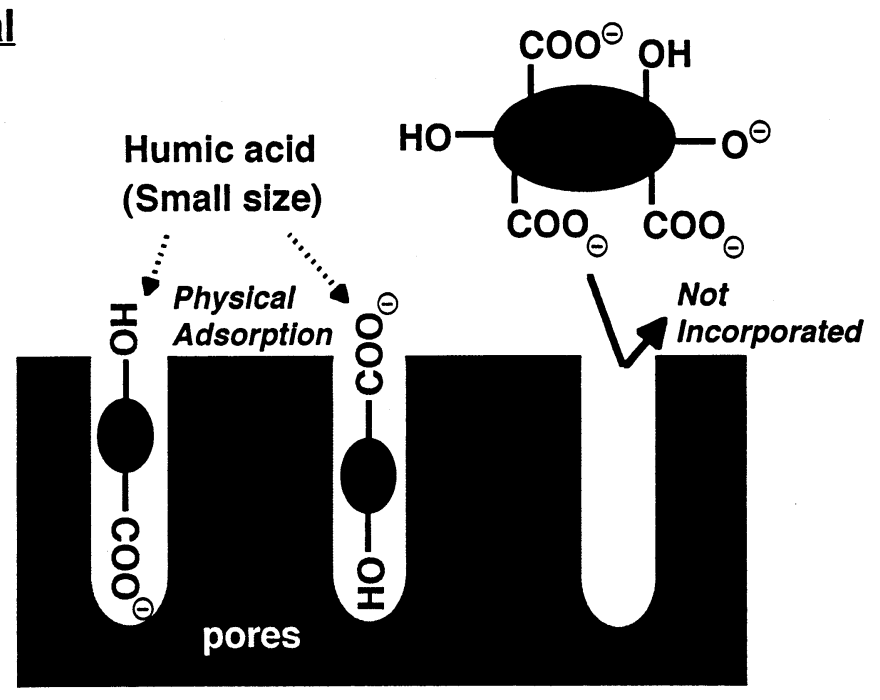

SCHEME 1 Schematic illustration of adsorption mechanisms of HA on HAP-300 (upper) and charcoal (lower).

\section{REFERENCES}

1. T. Moriguchi, K. Yano, S. Nakagawa, and F. Kaji, J. Colloid Interface Sci., 260, 19 (2003).

2. P. MacCarthy, R. L. Malcolm, C. E. Clapp, and P. R. Bloom, in Humic Substances in Soil and Crop Sciences: Selected Readings, edited by P. MacCathy et al. (ASA, SSSA, Madison, Wisconsin, USA, 1990), p. 1.

3. M. Wolf, G. Buckan, H. Geckeis, N. M. Thang, E. Hoque, W. Szymczak, and J. I. Kim, in Humic Substances: Structures, Models and Functions, edited by E. A. Ghabbour et al. (Royal Society of Chemistry, Cambridge, UK, 2001), p. 51.

4. E. M. Thurman, in Organic Geochemistry of Natural Waters, (Dordrecht; Boston; M. Nijhoff, Hingham, MA, USA, 1985), p. 312 
5. M. J. Piana and K. O. Zahir, J. Environ. Sci. Health, B35, 87 (2000).

6. K. J. Ives, in The Scietific Basis of Filtration, (Noordhoff International Pub., 1975), p. 203.

7. J. J. Rook, Water Treatment Exam., 23, 234 (1974).

8. N. Matsuda, F. Kaji, S. Nakagawa, T. Uemura, and M. Watanabe, Inorg. Mater. $\underline{5}$ 398 (1998).

9. S. Nakagawa, F. Kaji, T. Yamagami, M. Sakurai, and M. Watanabe, Phosphorus Res. Bull., 14, 119 (2002).

10. M. L. Cheng, H. Y. Ho, D. T. Y. Chiu, and F. J. Lu, Free Radical Biol. Med., 27, 470 (1999).

11. M. Kresak, E. C. Moreno, R.T. Zahradnik, and D. I. Hay, J. Colloid Interface Sci., $\underline{59}$, 283 (1977).

12. S. A. Hashsham and D. L. Freedman, Water Res., 37, 3189 (2003).

13. J. A. Rice, T. F. Guetzloff, and E. Tombacz, in Humic Substances: Versatile Components of Plants, Soil and Water, edited by E. A. Ghabbour et al. (Royal Society of Chemistry, Cambridge, UK, 2000), p. 135.

14. E. A. Braude, in Determination of Organic Structures by Physical Methods, (Academic, New York, USA, 1955), chapter 4, p. 131.

15. E. A. Braude, in Ann. Rep. Progress Chem., (Chemical Society of London, London, UK, 1945), XLII, p. 105.

16. E. M. Thurman, in Ref. 3, p. 279. 